\title{
40. The Effects of Pressure on Electric Resistance and Thermal Conductivity of Metals at Melting Points.
}

\author{
By Mizuho Satô.
}

(Comm. by K. Honda, M.J.A., July 12, 1950.)

\section{S. Introduction.}

In the previous paper ${ }^{1)}$ we have treated the effect of internal or transformation stress on electric resistance of pure Iron at $A_{3}$ point and obtained the result that the electric resistance increases and decreases in approaching $A c_{3}$ and $A r_{s}$ points respectively, in which the former is caused by tension accompanying the transformation $a \rightarrow \gamma$, while the latter is due to the pressure accompanying the transformation $\gamma \rightarrow \alpha$. This result has been confirmed by Prof. Mihara's observed fact very satisfactorily.

Since melting of metals is one of the transformation phenomena, it is evident that the same conclusion concerning the pressureeffect should also be applied on such eases, in which the melting begins from inside towards outside of the solid spheres, where the specific volume in liquid state is larger than that in the solid state. The results of calculation for several metals will be tabulated in this paper, though the experimental data at melting points are at present lacking, owing to difficulties accompanying high temperature measurements.

In the present paper the effect of transformation pressure on thermal conductivity of some metals at melting points will also be treated under the assumption that Wiedeman-Franz's law holds good for these metals, though this assumption can not be generally accepted under high pressures, as seen from Prof. Bridgman's experimental results ${ }^{2}$.

\section{\$2. Pressure Effect on Electric Resistance of Several Metals at Melting Points.}

The formula to be used for calculation of relative change of resistance $R$ by pressure $p$ is given by Prof. $\mathrm{Bridg} \mathrm{man}^{3)}$ in form of

1) M. Satô: Proc. Jap. Acad., 26 (1950), No. 6, 42.

2) P. W. Bridgman : Proc. Amer. Acad. Sci. Arts, 57 (1922), 77; The Physics of High Pressure, p. 328 published in 1931, London.

3) P. W. Bridgman: Phys. Rev., 9 (1917), 269. 


$$
\frac{1}{R}\left(\frac{\partial R}{\partial p}\right)_{T}=-\frac{2}{\rho} \frac{\beta}{c_{v}}-\frac{\kappa}{3},
$$

where $\beta$ is the thermal expansion coefficient, $\rho$ the density, $\kappa$ the isothermal compressibility and $c_{v}$ the specific heat at constant volume, whose values are calculated from the values of $c_{p}$ by means of well known thermodynamical relation.

Substituting the values of these constants at melting point in the above formula, we can calculate the relative change of resistance due to transformation pressure $\overline{\delta p}$, as is shown in the following table.

\begin{tabular}{|l|r|r|r|r|r|r|r|r|}
\hline \multirow{2}{*}{ Metal } & $\begin{array}{c}10^{\epsilon} \cdot \kappa \\
\mathrm{cm}^{2} / \mathrm{kg}\end{array}$ & $\begin{array}{c}10^{5} \cdot \beta \\
\mathrm{deg}^{-1}\end{array}$ & \multicolumn{1}{c|}{$\begin{array}{c}c_{v} \\
\mathrm{cal} / \mathrm{gr}\end{array}$} & $\begin{array}{c}\rho \\
\mathrm{gr} / \mathrm{cm}^{3}\end{array}$ & $\begin{array}{r}-10^{6} \cdot \frac{1}{R}\left(\frac{\partial R}{\partial p}\right)_{\mathrm{r}} \\
\mathrm{cm}^{2} / \mathrm{kg}\end{array}$ & $\begin{array}{c}\delta p \\
\text { atmos }\end{array}$ & $\begin{array}{r}-\frac{\delta R}{R} \\
\text { calc }\end{array}$ & $\begin{array}{r}-\frac{\delta R}{R} \\
\text { obs }\end{array}$ \\
\hline $\mathrm{Ag}$ & 4.47 & 7.98 & 0.0620 & 9.88 & 7.680 & 3980 & 0.03053 & \\
$\mathrm{Al}$ & 7.82 & 9.12 & 0.2649 & 2.57 & 9.050 & 2844 & 0.02572 & \\
$\mathrm{Au}$ & 6.26 & 5.145 & 0.0363 & 18.43 & 5.744 & 2940 & 0.01700 & \\
$\mathrm{Cd}$ & 15.95 & 9.207 & 0.0582 & 8.30 & 14.36 & 1053 & 0.01565 & \\
$\mathrm{Cs}$ & 62.11 & 29.10 & 0.0412 & 2.5 & 155.50 & 143 & 0.02222 & \\
$\mathrm{Cu}$ & 2.83 & 6.825 & 0.1063 & 8.42 & 4.040 & 5080 & 0.02050 & \\
$\mathrm{Fe}$ & 4.04 & 3.28 & 0.1614 & 7.39 & 2.660 & 3880 & 0.00516 & \\
$\mathrm{~K}$ & 32.39 & 24.90 & 0.1640 & 0.85 & 117.60 & 308 & 0.03630 & 0.04081 \\
$\mathrm{Na}$ & 15.94 & 21.30 & 0.2818 & 0.95 & 43.75 & 564 & 0.02470 & 0.04965 \\
$\mathrm{~Pb}$ & 39.5 & 9.63 & 0.0335 & 11.05 & 25.12 & 309 & 0.00776 & \\
$\mathrm{Rb}$ & 40.80 & 27.00 & 0.0772 & 1.51 & 124.00 & 217 & 0.02690 & 0.02890 \\
$\mathrm{Sn}$ & 9.10 & 6.90 & 0.0651 & 7.19 & 10.03 & 1000 & 0.01003 & \\
$\mathrm{Zn}$ (Poly) & 3.91 & 10.89 & 0.0925 & 7.05 & 9.250 & 5910 & 0.05467 & \\
\hline
\end{tabular}

The observed values of relative change of resistance for metals at melting points are at present lacking, and so the last column in the above table remains mostly blank, except a few cases of metals, for which extrapolation has been applied by making use of Prof. Bridgman's data at lower temperatures.

A number of data concerning the pressure-effect in temperature range from room temperature to $100^{\circ} \mathrm{C}$ has been found by Prof. Bridgman ${ }^{4}$. According to him, the relative change of resistance due to external pressure corresponding to transformation pressure has the same order of magnitude as that calculated at melting points. For instance, the relative change of resistance of Silber at $100^{\circ} \mathrm{C}$ due to the external pressure 3980 atmos is measured to be about $2.96 \%$, which is in a close agreement with the calculated value $3.05 \%$ at melting point. For others, the same is also the case.

4) P. W. Bridgman: The Physics of High Pressure, p. 263. 


\section{$\S 3$. Pressure Effect on Thermal Conductivity of Metals at Melting Points.}

There is an intimate relation between electrical and thermal conductivities of metals, as is shown by Wiedeman-Franz's law. It may be expected, therefore, that the thermal coductivity is affected by pressure in the same degrees as in the case of electric resistance. According to Prof. $\mathrm{Bridgman}{ }^{5}$, however, the Wiedeman-Franz's law does not hold exactly under extremely high pressures. In fact, he has obtained the pressure coefficient of Wiedeman-Franz's law; the change of thermal conductivity for some metals occurs in the same sense as that of electric resistance. In his experimental data the effects for Iron, Copper, Zirconium, Platin etc. are negative, while Lead, Cadmium, Tin and other minerals show the positive effects. Against these results Lussana ${ }^{6 r}$ has observed positive effects for various metals under several thousand atmospheres, finding that the thermal conductivity of metals is increased by pressure. In the present paper, the case in which Wiedeman-Franz's law is valid will be considered. At first the thermal conductivity $k$ is known to be proportional to the reciprocal of electric resistance $R$, then the relation to be used for testing becomes

$$
\frac{1}{k}\left(\begin{array}{c}
\partial k \\
\partial p
\end{array}\right)_{T}=-\frac{1}{R}\left(\frac{\partial R}{\partial p}\right)_{T} .
$$

As an example, in the case of Aluminium the relative change of resistance is $-2.57 \%$ at melting point, as given in the above table. Thus

$$
\frac{\delta k}{k}=2.57 \%
$$

The experimental data concerning this effect at melting point are lacking, and so this theoretical value can not be compared with experimental value. According to Lussanat, however, the relative change of thermal conductivity of Aluminium at $24.4^{\circ} \mathrm{C}$ by a pressure of 2844 atmos has been observed to be $2.34 \%$, which is the same order of magnitude as compared with that at melting. point. Further, if the values for Cadmium, Lead and Tin are taken from Lussana's data, it is found that the observed values are $1.33 \%$ at $23.7^{\circ} \mathrm{C}$ under 1053 atmos, $0.57 \%$ at $24.8^{\circ} \mathrm{C}$ under 309 atmos, and $0.76 \%$ at $23.7^{\circ} \mathrm{C}$ under 1000 atmos, rospectively.

5) P. W. BridgmaN : ibid. p. 328.

6) S. Lussana : Landolt-BöRnstein's Table, II (1923), 1289.

7) S. Lussana : ibid. 
The order of magnitude of these effects is the same as compared with the calculated values $1.57 \%, 0.78 \%$ and $1.00 \%$ at melting points, as seen from the above table listed with the relative changes of resistance.

\section{\$4. Conclusion.}

1. The electric resistance and the thermal conductivity of metals at melting points are affected by transformation pressure or simply pressure.

2. The decreases of electric resistance of some alkali metals at melting points caused by transformation pressure agree fairly well with the extrapolated values from Prof. Bridgman's data at lower temperatures.

3. The order of relative changes of electric resistance in metals at melting points caused by transformation pressure coincides with the same quantity due to the corresponding external pressure in the temperature range from room temperature to about $100^{\circ} \mathrm{C}$, at which Prof. Bridgman has carried out his experiments.

4. The increases of thermal conductivity of some metals at melting points caused by transformation pressure have the same order of magnitude as compared with the observed values by Lussana at ordinary temperatures.

In conclusion, the author wishes to express his hearty thanks to Dr. Kôtarô Honda, under whose valuable advices the present investigation has been carried out. 